Nathalie Stephens est une jeune écrivaine canadienne, bilingue, qui habite Toronto depuis quelques années. Elle a publié dans LittéRéalité et dans The Authors. Elle s'intéresse aux revendications féministes et, dans ce domaine, elle prépare une étude sur la condition des femmes noires à la Guadeloupe.

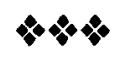

\title{
reveil
}

une éternitê violée par le temps

traine derrière toi

s'efface dans l'écume de l'oubli

vagues d'amertume passent sur ton corps

dêbordent dans ton esprit

t'inondent le coeur d'interminables souvenirs

d'un hier incompris

une odeur

un son

un frisson te frôle

éveillent en toi un sens d'avoir déjà été là

et tu détournes le regard du mur

qui t'empêche de voir

pour puiser un peu mais pas trop

dans ton toi antérieur

une goutte de feu

dans une plaie béante 
personne ne peut t'arracher

la terre qui t'habite

crie

sur la tombe

de la terre mourante

et ton cri

rencontrera l'écho

sourd de l'histoire

jette-toi

sur la tombe

de la terre mourante

et ton corps

apprendra l'isolement

de l'amour

répète

les dernières paroles

de la terre mourante

et ton âme connaîtra

le déchirement

de l'oubli

ton regard

l'emmurement

par le silence

personne ne peut t'arracher

la terre qui t'habite 


\section{Tanton Albè}

petit pays au grand coeur

où les hommes ont le ventre plein de feu

et les femmes charrient le bonheur à coups de pied

combien de canne coupée?

combien de canne brûlée?

broyée

dans la terre par l'homme avec l'homme

et la femme aussi

et la femme surtout

champs en feu comme le ventre de l'homme

un cri s'élève plus haut que le battement du ka

cris et coups

d'une femme êtendue sur son plancher

les enfants pendus à ses seins

et l'homme brandissant sa haine

se laisse emporter par la canne

et les femmes 
hommes à feu

petit pays au grand coeur au soleil levant

derrière cocotiers et plages blanches une âme se traîne parmi ces champs endiablés misère pour les malheureux agrippés à un quelconque espoir d'un avenir incertain quand les hommes éteindront le feu les femmes debout à côté d'eux

là seulement

solidarité

là seulement

fierté

construis pour ton monde pas le mien 